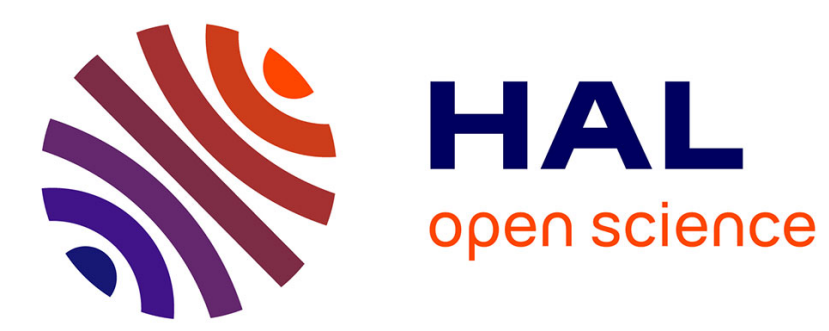

\title{
Pulsed photoacoustic study of collisional effects in IR multiphoton absorption measurements
}

\author{
J. Jovanic-Kurepa, D. Markusev, M. Terzic
}

\section{To cite this version:}

J. Jovanic-Kurepa, D. Markusev, M. Terzic. Pulsed photoacoustic study of collisional effects in IR multiphoton absorption measurements. Journal de Physique IV Proceedings, 1994, 04 (C4), pp.C4751-C4-754. 10.1051/jp4:19944206 . jpa-00252668

\section{HAL Id: jpa-00252668 https://hal.science/jpa-00252668}

Submitted on 1 Jan 1994

HAL is a multi-disciplinary open access archive for the deposit and dissemination of scientific research documents, whether they are published or not. The documents may come from teaching and research institutions in France or abroad, or from public or private research centers.
L'archive ouverte pluridisciplinaire HAL, est destinée au dépôt et à la diffusion de documents scientifiques de niveau recherche, publiés ou non, émanant des établissements d'enseignement et de recherche français ou étrangers, des laboratoires publics ou privés. 


\title{
Pulsed photoacoustic study of collisional effects in IR multiphoton absorption measurements
}

\author{
J. JOVANIC-KUREPA, D.D. MARKUSEV and M. TERZIC* \\ Institute of Physics, P.O. Box 57, 11001 Belgrade, Serbia, Yugoslavia \\ * University of Novi Sad, P.O. Box 224, 21001 Novi Sad, Serbia, Yugoslavia
}

\begin{abstract}
The pulsed laser photoacoustic technique, simultaneously used with transmission spectroscopy, was applied for detailed study of IR multiphoton absorption processes in polyatomic molecules. Collisional effects were specially investigated in $\mathrm{SF}_{6}$ diluted with $\mathrm{Ar}$ as nonabsorbing species. The results regarding the enhanced absorption cross sections $\left(\sigma^{\mathrm{e}}\right)$ for $\mathrm{SF}_{6}$-Ar mixtures are obtained with precision of $\pm 18- \pm 29 \%$. The differential absorption cross sections $\left(\sigma_{d}^{e}\right)$, as well as the average number of absorbed photons $<\mathrm{n}>$ per $\mathrm{SF}_{6}$ molecule in 0,1 $-0,7 \mathrm{~J} / \mathrm{cm}^{2}$ fluence range and $1-140 \mathrm{mbar}$ Ar pressure range are also presented.
\end{abstract}

\section{Background Information}

The effects of the buffer gas on multiphoton absorption (MPA) in $\mathrm{SF}_{6}$ have been in the past [1] and recently very thoroughly studied $[2,3]$ mainly by transmission spectroscopy techniques (TRS). The important characteristics of MPA processes have been determined as: absorption cross sections $\left(\sigma^{e}\right)$ and differential absorption cross sections $\left(\sigma_{d}^{e}\right)$ rotational and translational temperatures, etc. under the collisions of the different buffer gases, but primarily in details in the time scale adequate to laser pulse duration time $[2,3]$.

The aim of this contribution is to present the MPA data obtained by application of calibrated pulsed laser photoacoustic apparatus (PAS) for $\mathrm{SF}_{6}$ diluted by a typical buffer gas Ar. This experiment incorporates two techniques used simultaneously: PAS as the measurement method of the phenomena, and the TRS as the absolute method used for normalization purposes. Our main goal was to overcome the shortcomings of TRS method [4], and use PAS due to their high sensitivity as its primary advantage. Such approach requires very precise calibration procedure for used the photoacoustic gas cell-detector system, $i$, e. the determination of the calibration factors $S(\mathrm{p}, \gamma, \mathrm{T})$ as the function of the pressure in the cell $(\mathrm{p})$, of the gas nature $\left(\gamma=\mathrm{C}_{\mathrm{p}} / \mathrm{C}_{\mathrm{v}}\right)$ and the ambient temperature (T). The sensitivity of the setup is given by eq. (1) obtained under the assumption that the absorption cross sections by TRS and PAS methods are identical. All details about photoacoustic signal $\left(\mathrm{P}_{\mathrm{a}}\right)$ normalization procedure, are given elsewhere [5].

$$
S(p, \gamma, T)=\frac{E_{i}}{P_{a}}\left[1-\frac{E_{i}}{E_{t}}\right]^{-\frac{l_{m}}{L}}
$$

With $1_{m}$ and $L$ the lengths of the microphone and the gas cell are denoted respectively. $E_{i}$ and $E_{t}$ present corrected incoming and transmitted laser excitation energies, but the $P_{a}$ is the relevant photoacoustic signal. The $S(\mathrm{p}, \gamma, \mathrm{T})$ values obtained, have been easily fitted to the 
equation shape $S(p, \gamma, T)=A p_{A r}^{B}+\gamma$ what is in accordance with proposed theoretical model for a nonresonant photoacoustic cell [6].

This paper reports the results regarding the MPA processes in $\mathrm{SF}_{6}\left(\mathrm{p}_{\mathrm{SF} 6}=0,47 \mathrm{mbar}\right)$ obtained for $\mathrm{SF}_{6}$-Ar mixtures irradiated by a parallel laser beam of the $10 \mathrm{P}(16) \mathrm{CO}_{2}$ laser line. They are: the enhanced absorption cross sections $\left(\sigma^{\mathrm{e}}\right)$ and the differential absorption cross sections $\left(\sigma_{d}^{e}\right)$. $\sigma^{e}$ data show the ability of $\mathrm{SF}_{6}$ molecule to accept the laser photon starting

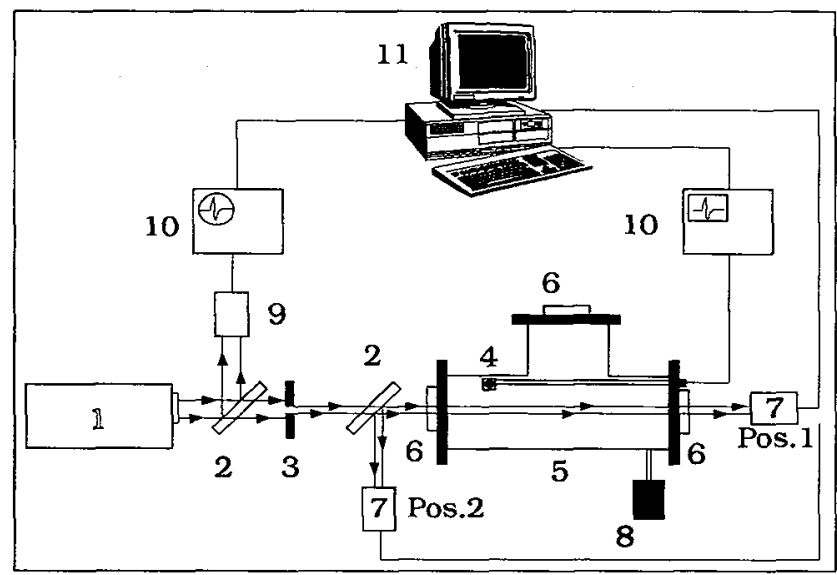

Figure 1. Experimental apparatus: 1-TEA CO, laser, 2-beam splitter, 3-blind, 4-microphone, 5-PA cell, 6-cell windows, 7-joulemeter, 8-pressure control, 9-photon-drag detector, 10- oscilloscopes, 11-PC computer, POS 1- for TRS and POS 2-for PAS measurements.

from the vibrational ground state, while $\sigma_{d}^{e}$ show the ability to accept another photon for already vibrationaly excited molecule.

\section{Experimental Apparatus}

The experimental apparatus (Fig. 1) basically consist of three main parts: the photoacoustic cell (background pressure $\sim 10^{-6}$ mbar) with two $\mathrm{NaCl}$ windows and build in photoacoustic detector, data acquisition and processing system, and a line tunable TEA pulsed $\mathrm{CO}_{2}$ laser (Tachisto $215 \mathrm{G}$ ). The photoacoustic cell is a cylindrical three-port stainless-steel vacuum chamber designed to satisfy requirements for simultaneous use of PAS and TRS techniques [5]. The gas pressure in the cell was monitored by a capacitance manometer. The acoustic wave form ( $P_{z}$ is its amplitude) and also the laser excitation $\left(E_{i}\right)$ and transmitted $\left(E_{v}\right)$ energies were digitized by a waveform recorder. Data acquisition and processing were performed by a personal computer. However, the acoustic wave forms were stored only for subsequent analysis if $\mathrm{E}_{\mathrm{i}}$ or $\mathrm{E}_{\mathrm{t}}$ measurement of $\mathrm{E}_{\mathrm{i}} \pm 10 \%\left(\mathrm{E}_{\mathrm{t}} \pm 10 \%\right)$ were detected.

\section{Experimental Results and Discussion}

Our MPA experiment in $\mathrm{SF}_{6}$-Ar mixtures has been performed in two different arrangements [5]. The first one served for the photoacoustic's signal $\left(\mathbf{P}_{2}\right)$ calibration, i. e. to determine for every gas mixture and every gas pressure $S(\mathrm{p}, \gamma, \mathrm{T})$ value. Also, the $S(\mathrm{p}, \gamma, \mathrm{T})$ independence of laser fluences was checked. The second one was devoted to accumulation of the relevant $\mathrm{P}_{\mathrm{a}}$ data necessary to determine $\sigma^{\mathrm{e}}$. This quantity is defined, in terms of PAS parameters, as 


$$
\sigma^{e}=\frac{-1}{N l_{m}} \cdot \ln \left[1-\frac{S(p, \gamma, T) P_{a}}{E_{i}}\right]
$$

what is appropriate presentation of Beer-Lambert absorption law. $\mathrm{N}$ in eq. (2) is the relevant concetracion of $\mathrm{Ar}$ atoms in the cell.

The differential absorption cross sections $\sigma_{d}^{e}$ are usually given as $\sigma_{d}^{e}=h v \mathrm{~d}<\mathrm{n}>/ \mathrm{d} \phi$, but for our investigated medium laser fluence range $0,1-0,7 \mathrm{~J} / \mathrm{cm}^{2}$, he is given by eq. (3).

$$
\sigma_{d}^{e}=\frac{S(p, \gamma, T)}{4 \cdot 10^{4} N l_{m}} \cdot \frac{d\left(P_{a}\right)}{d E_{i}}=\beta \sigma^{e}
$$

On Fig. 2a. the enhanced absorption cross sections $\left(\sigma^{e}\right)$ are given for typical fluences: $0,49,0,30$ and $0,19 \mathrm{~J} / \mathrm{cm}^{2}$. On Fig. $2 b$. the relevant values for $<n>$ are shown for the previously cited fluences and $1-140$ mbar Ar pressure range. Also, The comparison with proposed theoretical model [7] is given (full lines on Fig. 2b.), i. e. that $<\mathrm{n}>\sim p_{A r}^{0,3}$.

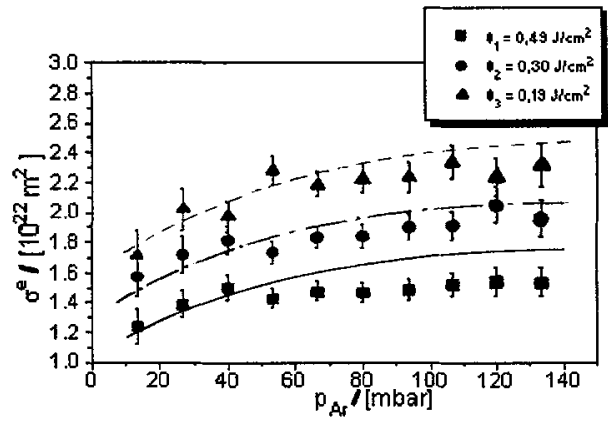

Figure 2a. The enhanced absorption cross section $\sigma^{*}$ dependence of Ar pressure, for different laser fluences

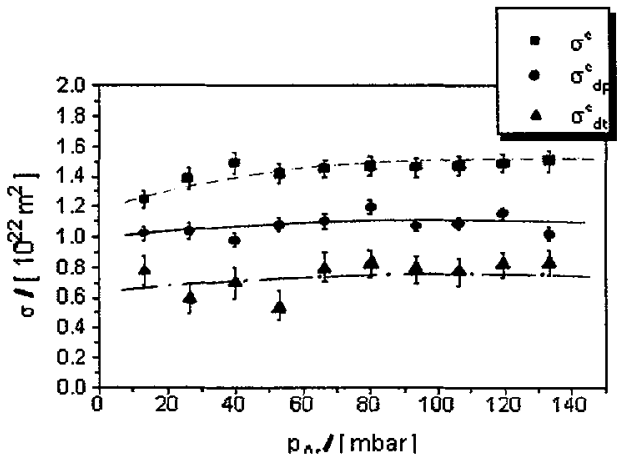

Figure 3a. Differential cross sections dependence of Ar pressure and comparison between $\sigma^{c}$ (PAS), $\sigma_{\phi}^{c}(\mathrm{PAS})$ and $\sigma_{\alpha}^{c}$ (TRS) values.

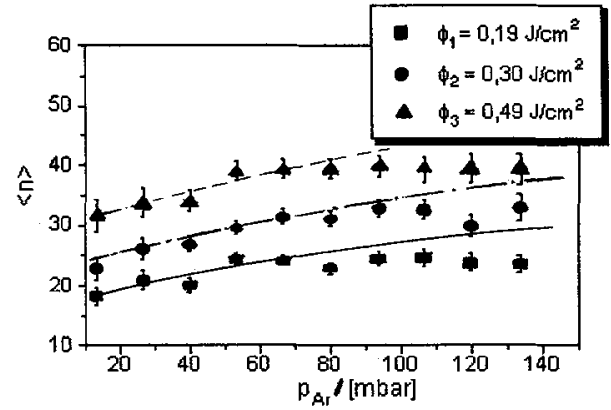

Figure 2b. Relevant values for $<\mathrm{n}>$ dependence of Ar pressure, for different laser fluences

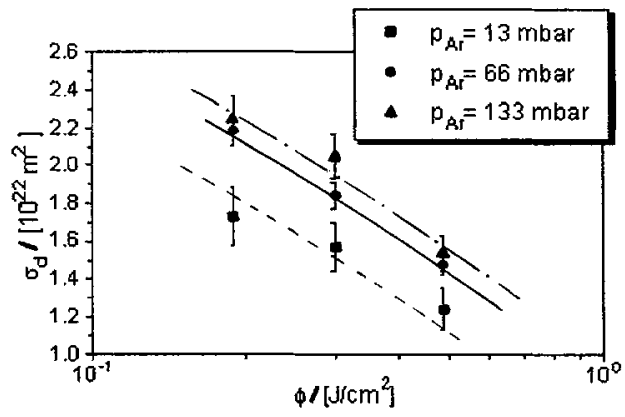

Figure $3 \mathrm{~b}$. Differential cross sections fluence dependence for different Ar pressure

Figures $3 \mathrm{a}$. and $3 \mathrm{~b}$. show the experimental results for $\sigma_{d}^{e}$ as the function of the gas pressures (Fig. 3a.) and the laser fluences (Fig. 3b.) for three different Ar pressures (13,66 
and $133 \mathrm{mbar}$ ). On Fig. 3a. the results for $\sigma^{e}$ very clearly demonstrate that $\sigma^{e} \geq \sigma_{d}^{e}$, i. e. that $\beta<1$, (see eq. (3)), as well as some our expectation. Namely, $\sigma_{d}^{e}$ obtained from relation given above $\left(\sigma_{d t}^{e}=h v \cdot d<n>/ d<\phi>\right)$, include possible systematic error due to incorrect determination of laser beam diameter in front of the microphone, and also all statistical errors incorporated in $<n>$ and $\phi$ quantities. When eq. (3) is used for direct $\sigma_{d}^{e}$ calculation, the more precise results are obtained and they are given as curve 2 (Fig. 3a.). On another hand, Fig. 3b. gives the data obtained for $\sigma_{d}^{e}$ as the function of the laser fluences, and show rather expected behavior for medium fluence range, the substantial decrease of $\sigma_{d}^{e}$ with the increase of $\mathrm{Ar}$ pressure. All the obtained results have been determined with the precision range $\pm 18 \%- \pm 29 \%$.

\section{Conclusions}

The pulsed photoacoustic setup is build for the quantitative investigation of MPA processes in medium fluence range. It is devoted to primarily IR spectral range for study of polyatomic species and their buffer gas mixtures. The measurements of $\sigma^{e}, \sigma_{d}^{e}$ and $\langle\mathrm{n}\rangle$ are our main tasks. The reasons are the better understanding of the collisional effects in MPA processes. Also it was of interest to find out the optimal IR gas absorber and its optimal buffer gas partner, to be used in the research field of laser induced syntheses of special materials.

\section{References}

[1] "Multiple-Photon Excitation and Dissociation of Polyatomic Molecules", Ed. by C. D. Cantrell, Springer-Verlag, (1986), 9

[2] M. Lenci, E. Molinari, G. Piciachia, V. Sessa, M. L. Terranova, Chem. Phys., 108, (1986), 167

[3] M. Lenci, E. Molinari, G. Piciachia, V. Sessa, M. L. Terranova, Chem. Phys., 142, (1990), 473

[4] S. L. Chin, D. K. Evans, R. D. McAlpine and W. N. Selander, Appl. Opt., 11, (1982), 65

[5] J. Jovanovic-Kurepa, M. Terzic, D. D. Markusev and P. Vujkovic Cvijin, submitted to Measur. Sci. and Techn.

[6] D. R. Wake and N. M. Amer, Appl. Phys. Lett., 34, (1979), 379

[7] O. P. Judd, J. Chem. Phys., 71, (1979), 4515 